\title{
Interviews
}

\section{Interview with Hannah Barker}

Winner of the Paul E. Lovejoy Prize

Hannah Barker, the winner of this year's Lovejoy Prize with her book That Most Precious Merchandise: The Mediterranean Trade in Black Sea Slaves, 1260-1500 (Philadelphia: University of Pennsylvania Press, 2019), is an assistant professor of history at Arizona State University. Her research interests center around ideologies and practices of slavery in the medieval Mediterranean, especially the slave trade from the Black Sea to the markets of Cairo, Genoa, and Venice during the thirteenth through fifteenth centuries. The jury members of the JGS were keen to interview her about her work and her future research plans.

How didyou come to research this particular trade in the first place, and what were your intentions for doing so?

When I applied to graduate school, I was interested in long-distance travel and interactions across religious and cultural boundaries. I had already committed to learning Arabic as well as Latin, but I didn't have any particular interest in the slave trade at that point. As it turned out, in my first semester my advisor (Adam Kosto) was co-teaching a seminar on Captivity with an American historian (Evan Haefeli), so I thought I had better take it. I struggled at the time to find a good research topic, attempted to write about slavery in Caffa, and was deeply dissatisfied with the result. However, in the process of writing that awful paper I realized just how much room there was for new research on the subject, and that using both Arabic and Latin sources to approach it would give me a different perspective than previous scholars. The more I worked on it, the more strange and surprising things I discovered. So I continued with the same topic for my master's thesis, my doctoral dissertation, and the book. Even now, I'm still finding strange and surprising things in the medieval sources. 
How does your book change the way scholars think about Mediterranean slavery in the late medieval period?

The two big ideas about Mediterranean slavery that I hope scholars take away from my book are that 1) slavery was an important field of interaction between adherents of different religions, and 2) it is not helpful to project assumptions based on the trans-Atlantic model of slavery backward in time.

In connection with the first point, I decided to argue for a common culture of slavery in the late medieval Mediterranean, one shared by Christians, Muslims, and (I would expect, but it's not my area of expertise) Jews. That does not mean that Christians, Muslims, and Jews practiced slavery in exactly the same way. However, I think that the previous literature has tended to silo the history of slavery along religious lines and to put more weight on differences than on similarities in the practice of slavery. I wanted to put more weight on the similarities, since there are so many of them! I also want to emphasize that slavery was an area of interaction: members of different religions enslaved one another and traded slaves with one another regularly. In that context, it would be odd if they did not share certain basic assumptions about what slavery was and how it worked. Since finishing the book, I've done some reading on slavery in pre-Columbian American societies, and it's fascinating to see which aspects of slavery seem to have developed along parallel lines in radically different cultures and which aspects seem distinctive to the Mediterranean.

In connection with the second point, I noticed how strongly the literature on medieval slavery (in the Mediterranean and elsewhere) has been shaped by assumptions derived from the Atlantic, or to a lesser extent the Greco-Roman, context. I started out with those assumptions as well, but one by one I found them to be misleading. The majority of slaves in the late medieval Mediterranean were not male, they were not necessarily Black (or racialized in other ways that we are familiar with), they were not engaged in agricultural labor, they were not traded by specialist merchants or companies, they were not transported on specialized ships, and the existence of slavery was not subject to moral critique. That is a lot of mental baggage to set aside, especially for an American, and I'm sure there are one or two places in the book where I slipped into old habits of thought. Still, I hope my work helps other scholars resist the urge to generalize and instead to consider how many locally and temporally distinctive forms slavery can take. I also hope it helps others see just how unprecedented the trans-Atlantic slaving system was.

In reading your book we were struck by the huge variety of statuses and experiences of enslaved persons so vividly portrayed in it. We also took note of your critique of generational chauvinism and your plea that historians not apply 
modern rationales and normative judgments in their analyses of medieval societies. Given your findings and interpretations, do you find for example Patterson's definition of slavery as a form of "social death" useful to the study of medieval Mediterranean and Black Sea slavery?

Generally speaking, I do think Patterson's idea of slavery as a form of social death is useful. The range of statuses and experiences associated with slavery is so broad that it's valuable to have some kind of metric for explaining what is similar and what is different in each case. I also find the idea of social death useful for explaining why elite slaves still experienced slavery as trauma, why enslaved people in positions of wealth and power over others still sought to resist or escape that status. I don't want to apply Patterson's definition too rigidly, though. I tend to think of it as a set of criteria for articulating how one form of slavery can look very different from another, but both forms can exist together on the same spectrum. As a counterpoint, I also find Joseph Miller's definition of slaving as a strategy and enslavement as an experience helpful because it emphasizes the individuals operating within these broader systems.

How might your work relate to other studies of slavery across time and space, such as for example the work of Paul Lovejoy - the prize's namesake-on slavery in West Africa?

What I like about Paul Lovejoy's work is the balance between the big-picture discussions of slavery as part of a complex economic system and the detailed focus on individual experience and the perspectives of specific enslaved people. There are fewer surviving sources from the medieval period written by or directly reflecting the experiences of a specific enslaved person, but that makes those rare sources especially interesting and valuable. I also appreciate Lovejoy's argument against "the false impression that Africa's involvement in the slave trade was somehow passive, ahistorical, and only of interest in examining victimization and seemingly progressive underdevelopment" (from the preface to the third edition of Transformations in Slavery, p. xxi). Similar things could be said about the study of medieval slaving in the Black Sea, which has often been treated by historians of the Mediterranean as a black box from which slaves simply appeared. Of course, the present-day implications of those two cases are different, but I think all historians can benefit by avoiding that kind of passive framing around how people become enslaved and enter the slave market.

\section{What is the relevance of your study for contemporary society?}

As a society, we are experiencing a moment of heightened consciousness about and discussion of racism and systemic oppression. I want people to realize just how deeply rooted this history of oppression is and to take seriously the diffi- 
culty of making change in the face of such inertia. On the other hand, oppressive practices and ideologies have changed over time; the way they operated in the fourteenth century was quite different, though not entirely different, from the way they operate today. If that is true, then it is possible for more changes to happen. The most important change of all, in my view, is the present consensus that slavery is an absolute moral wrong and should be universally illegal. That was not a matter of consensus in the past, so the fact that it is widely accepted now is meaningful and grounds for hope.

\section{What will be your next project?}

My next project is about the intersection of race and slavery in medieval Italian legal sources. As an opening question, I am asking how Italian notaries categorized slaves, and whether it is analytically useful to talk about those categories in terms of race. In other words, when a slave was described as a Tatar (a Moor, a Greek, etc.) in a legal document, what exactly did that label imply? Where did notaries get these labels, and how did they decide which labels to assign to which slaves? Was it possible to change labels, i.e. could a person become a Tatar or cease to be a Tatar? This project was inspired by my early archival research, when I began to notice documents in which notaries made mistakes, crossing out one label and replacing it with another. I addressed this notarial confusion around race briefly in the second chapter of my book, but a lot more work remains to be done on this topic.

Journal of Global Slavery Editorial Team 